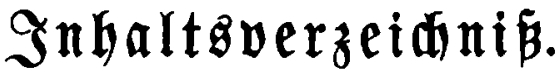

Sette

Einleitung. . . . . . . . . . . . . . . . 1

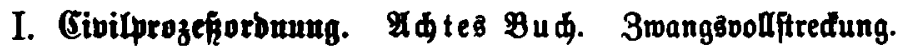

Erfter \&bfdnitt. Allgemeine Beftinumungen . . . . . . . . . . . 33

3reiter 26 f́nnitt. 3wang8vouftredung wegen Celbforberungen . . . . 112

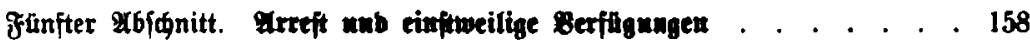

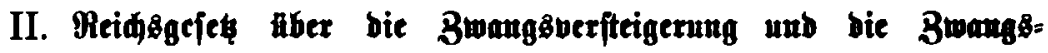
vermaltung.

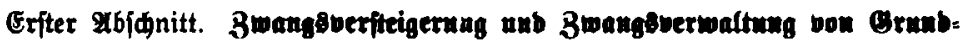

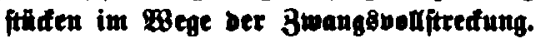

Erfter Titel. Allgemeine Borfdriften. $\$ \$ 1-14$. . . . . 169

3weiter Titel. 3wangs̄oeriteigerung.

I. Ynorbnung ber Berfteigerung. \$15-27 . . . . . . . 204

II. Xufhebung unb einftreilige Einftellung beă Berfabrens. $\$ \$ 28-34$. . . . . . . . . . . . . . . . . 227

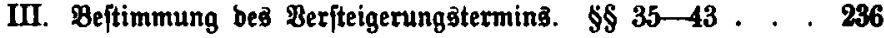

IV. Beringftes Bebot. Beriteigerungabebingungen. $\$ \$ 44-65246$

V. Derfteigerung. $\$ \$ 66-78$. . . . . . . . . . . . . 296

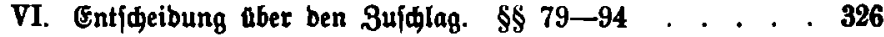

VII. Bejhmerbe. $\$ 95-104$. . . . . . . . . . . . 369

VIII. Bertbeilung bes Erlö́fes. $\$ \$ 105-145$. . . . . . . 383

Dritter Ritel. 3wang ḡverwaltung. $\$ \$ 146-161 \quad . \quad . \quad . \quad .484$

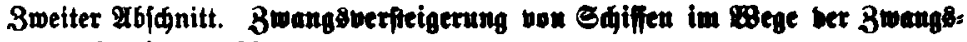
voufreelung. $\$ \$ 162-171$. . . . . . . . . . . . . . . . 537

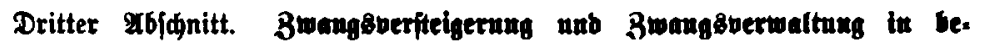

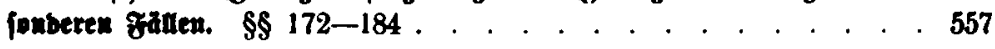

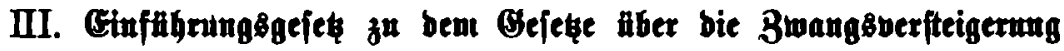
unb bie 3wangsverwaltung . . . . . . . . . . . . . . . . 593

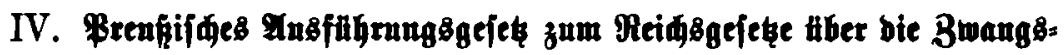
verfteigerung unb bie 3wangsoerwaltung.

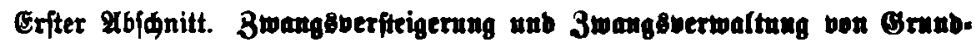

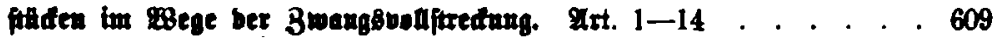




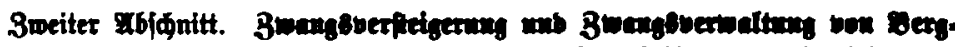
Sette

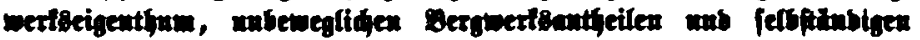

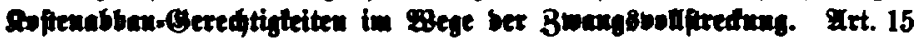
bis 21

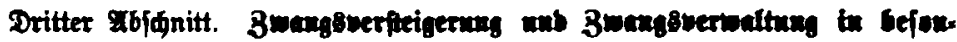
berex Giflen. Êt. 22-32 . . . . . . . . . . . . . . . . 632

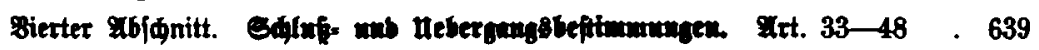

V. Allgemeine Berfigung bes Inftizminifter pom 8. Dezember 1899,

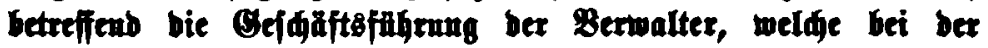
3wangsverwaltung beftellt werben, unb bie ben Berwaltern zu getwähreube Bergütung . . . . . . . . . . . . . . . . . . 65

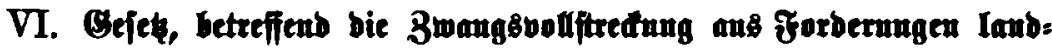
idaftlidigex (ritteridjaftlider) Stebitauftalten

VII. Berorbunug, betreffenb bas Berwaltungszomangsuerfagren wegen

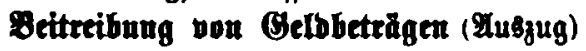

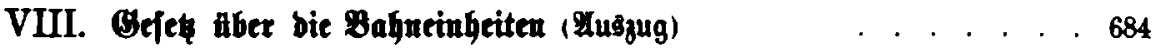

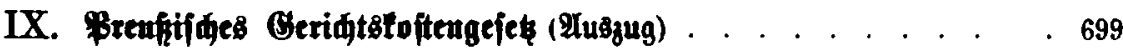

$X$. Beję, enthaltend bic Ianbesgejęliden Boridriften ther bie

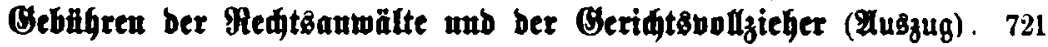

XI. Die in Prenken geltenben Bef́tinunungen äber freimillige Bers fteigerungen von Grumbitliden . . . . . . . . . . . . . . 729

Sadregifter

\section{E $\mathfrak{x} \mathfrak{g} \mathfrak{a} \mathfrak{n} \mathfrak{z} \mathfrak{u} \mathfrak{u} \mathfrak{g}$.}

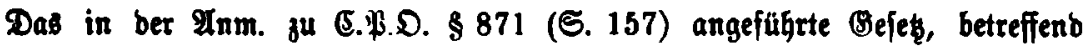
bas Pfanbredit an Privateifenbagnen unb Sleinbahnen und bie 3rongsoolfftredung in biejelben, vom 19. 2ugujt 1895 ift inzwijden geänbert unb fügrt jeşt bie Bezeidnung "Befe über bie Bahneinbeiten". Das Befes ift in feiner jegigen gaffing augizugeweife unter VIII (S. 684) abgebrudt. Der frübere $\$ 58$ ift in ber neuen fraffung \$, 54 geworben. 